\title{
Editorial
}

\section{Conflitos por água e a injustiça ambiental}

\author{
Luciano Zanetti Pessôa Candiotto
}

O segundo número de AMBIENTES: Revista de Geografia e Ecologia Política é composto por nove artigos, sendo cinco deles relacionados ao tema "água", e ainda uma resenha. Muito embora os demais artigos sejam bastante relevantes, tratando de assuntos que vão de contaminação ambiental a desastres, passando por erosão dos solos e o papel dos catadores de lixo, a temática central deste número são as questões político-ambientais que giram em torno da problemática do acesso à água.

Inicialmente, ao apresentar o dossiê “Água, política e natureza”, Wagner Costa Ribeiro provoca os leitores a refletirem e perceberem como esse tema permite a integração de conhecimentos e abordagens geográficas. Ao demonstrar que novas preocupações vêm surgindo, sobretudo no contexto de lutas e conflitos por água, indica algumas perspectivas de análise.

O primeiro artigo do dossiê, intitulado "Conflito pela água, entre a escassez e a abundância: Marcos teóricos", de Wagner Costa Ribeiro, Cinthia Leone dos Santos e Luis Paulo da Silva, discorre sobre conflitos por água, seja em virtude de sua abundância, mas, principalmente, de sua escassez, conduzindo a injustiças ambientais. Os autores discutem conceitos como mercantilização e remunicipalização da água; apresentam abordagens de outros pesquisadores; e propõem um roteiro de análise conceitual e teórico direcionado a classificar conflitos pela água.

Considerando a relevância dos comitês de bacias hidrográficas no processo de gestão ambiental de águas e territórios, o artigo "Gestão das águas, comitês de bacias 
hidrográficas e resolução de conflitos ambientais", de autoria de Paulo Gusmão e Bianca Pavão, discute a eficácia e limites dos comitês de bacias hidrográficas enquanto fóruns dedicados à resolução de conflitos ambientais. Analisando exemplos de negociações em comitês de bacias hidrográficas nos estados do Ceará, do Rio de Janeiro e na Bacia do Rio Paraíba do Sul (que envolve os estados de São Paulo e Rio de Janeiro), os autores discutem se os processos decisórios que ocorrem no âmbito desses colegiados têm ou não contribuído para a superação de processos de injustiça ambiental existentes.

Com base em autores clássicos da Ecologia Política, Carlos Bordalo resgata parte da trajetória dessa "perspectiva metodológica interdisciplinar" para explanar sobre tipos de conflitos ambientais relacionados à água. Em "Os conflitos socioambientais pelo uso da água no Brasil na perspectiva da Ecologia Política", o autor apresenta dados sobre conflitos pelo acesso e uso da água no Brasil, com base em relatórios da Comissão Pastoral da Terra (CPT), comparando os conflitos nos anos de 2010, 2014 e 2018, e também discute o acesso à água enquanto direito humano.

A partir de uma preocupação metodológica no tocante a abordagens geográficas acerca da água, Luciano Candiotto argumenta sobre a relevância das microbacias hidrográficas, especificamente sobre microbacias diminutas, denominadas "dimicrobacias", como unidades de análise e de ação. Ao entender que a "dimicrobacia” possibilita a integração entre conhecimentos naturogênicos e sociais, o artigo "A "dimicrobacia" hidrográfica enquanto escala de análise e de ação: Reflexões com base na Ecologia Política e na Geografia Ambiental" discorre sobre os conceitos de ciclo hidrossocial e de bacia hidrográfica, e aponta caminhos e questões para se incorporar a "dimicrobacia" no contexto de atividades de pesquisa, ensino e extensão, considerando também ativismos ambientais.

Ao discutir um tema atual - alarmante, porém comumente ocultado pela mídia -, Marcos Mondardo estabelece uma relação entre a contaminação das águas por agrotóxicos em territórios Guarani e Kaiowá, no estado do Mato Grosso do Sul, com 
interesses e negligências por parte de agricultores e políticos (governos) vinculados ao agronegócio, os quais têm promovido o que denomina ataques químicos. Assim, o artigo "O governo bio/necropolítico do agronegócio e os impactos dos agrotóxicos sobre os territórios de vida Guarani e Kaiowá" encerra o dossiê sobre água, ressaltando a luta indígena para retornar a territórios de vida tradicionalmente ocupados (tekoha) e denunciando de forma veemente, processos de violência química contra grupos indígenas.

A maior parte dos demais artigos deste número gravita, cada um ao seu modo, ao redor de temas ligados a injustiças e problemas ambientais, como contaminação ambiental, más condições de trabalho, "gestão de riscos" e degradação ambiental decorrente da falta de práticas de conservação de solos.

No artigo "Políticas públicas para gestão de riscos: Aquisição de direitos ou reprodução da injustiça ambiental? Reflexões baseadas no caso do bairro Córrego D'Antas, Nova Friburgo (RJ)", Nathalia L. de Carvalho analisa como (não) se deu a participação da comunidade local no processo de instalação do sistema de alerta e alarme contra desastres em um bairro da Região Serrana do Rio de Janeiro. A autora questiona algumas políticas públicas para a "gestão de riscos", como de remoções de pessoas, que têm reforçado processos de desterritorialização e segregação sócio-espacial.

Ao relatar duas consequências ambientais da atuação da Companhia Siderúrgica do Atlântico - CSA no bairro de Santa Cruz, município do Rio de Janeiro (inundações e contaminação do ar), o artigo "Examinando a injustiça ambiental a partir da contaminação do ar e de inundações nos arredores da Companhia Siderúrgica do Atlântico/Ternium, às margens da Baía de Sepetiba (Rio de Janeiro)", de Thiago Tavares, estabelece uma relação com o debate teórico sobre justiça ambiental. Através da análise de contradições entre as consequências ambientais e as estratégias de marketing e cooptação da comunidade do referido bairro por parte da empresa CSA, o autor demonstra como o discurso do "desenvolvimento econômico" tem sido utilizado para se naturalizar desastres e injustiças. 
No artigo "Uso da terra pela agropecuária e sua relação com a erosão dos solos no município de Regente Feijó /SP", Alessandro D. de Santana demonstra como, entre 2006 e 2017, parte das áreas de pastagem (que são majoritárias) tem sido substituída por lavouras temporárias, sobretudo de cana-de-açúcar. Centrando sua análise nas características pedoclimáticas e na expansão de processos erosivos no município, que se dá em virtude de um manejo agropecuário sem preocupação com a adoção de medidas conservacionistas do solo, são evidenciadas práticas que deixam o solo mais suscetível à erosão, como a pecuária e as lavouras temporárias de milho, algodão e soja.

Para finalizar a seção de artigos, Bruno Farias apresenta resultados de uma pesquisa voltada para a análise das condições de trabalho de catadores de resíduos sólidos no município de Rio Grande: é o trabalho "O(s) porquê(s) da não inserção dos grupos de catadores que atuam nas unidades de triagem (UT's) do sistema de coleta seletiva municipal no planejamento e na gestão dos resíduos sólidos em Rio Grande (RS)". Estabelecendo uma relação com preceitos da Política Nacional dos Resíduos Sólidos (PNRS), institucionalizada através da Lei $n^{\circ} 12.305$ e do Decreto $n^{\circ} 7.404$, ambos de 2010, o autor identifica problemas de gestão por parte da Prefeitura municipal de Rio Grande, vinculados, principalmente, à superexploração da mão de obra dos catadores.

A resenha "Criando um clima", da autoria de Marcelo Lopes de Souza, analisa o conteúdo do livro "Weathered: Cultures of Climate", do climatologista Mike Hulme. Souza destaca o questionamento de Hulme sobre a neutralidade dos cientistas, indicando como o polêmico tema das mudanças climáticas e do aquecimento global está envolto por interesses políticos e econômicos, traduzidos em desinformação ou em informações enviesadas por parte da mídia, sem contar as próprias divergências entre cientistas. Na referida resenha, são destacados alguns apontamentos de Hulme acerca de uma Climatologia Cultural, campo fascinante e ainda novo, e a relevância de apreendermos as relações de poder e as visões de mundo envolvidas no debate sobre $\mathrm{o}(\mathrm{s})$ clima(s) e o futuro das sociedades. 